\title{
REPRESENTAÇÃO GRÁFICA E ENCAIXE DE MOLDES EM TECIDOS LISTRADOS
}

\author{
Imaging and fitting mould in woven striped
}

\section{ALVES, Andressa Schneider, I Doutoranda}

Universidade Federal do Rio Grande do Sul - UFRGS

andressaschneideralves@gmail.com

\section{AYMONE, José Luís Farinatti I Doutor em Eng. Civil}

Universidade Federal do Rio Grande do Sul - UFRGS

aymone@ufrgs.br

\section{Resumo}

Este trabalho tem como objetivo apresentar o encaixe de moldes da indústria do vestuário em tecidos listrados e um algoritmo para a resolução do problema. A metodologia utilizada constitui-se das seguintes fases: pesquisa bibliográfica, identificação das restrições, proposta do algoritmo e testes. A abordagem apresentada para o problema obteve alta eficiência de encaixe em testes manuais e será implementada em um software em desenvolvimento.

Palavras-chave: Encaixe; Moldes; Moda; Vestuário.

\section{Abstract}

This work aims to present the nesting problem applied to striped fabric in the garment industry. An algorithm for solving the problem is proposed. The methodology used has the following steps: literature review, identification of constraints, algorithm proposition and tests application. The presented approach obtained high efficiency in manual testing and will be implemented in a software, which is being developed.

Keywords: Nesting; Patterns; Fashion; Clothing. 


\section{INTRODUC̣ÃO}

O setor têxtil e de confecção obteve um faturamento aproximado de US\$ 56,7 bilhões em 2012 (STECANELLA, 2013). O gasto estimado das famílias brasileiras com produtos têxteis e de vestuário foi de $R \$ 102$ bilhões em 2012 . O Produto Interno Bruto (PIB) da cadeia têxtil e confecção, em que estão incluídas as indústrias têxtil, confecção e o setor de varejo somou $\mathrm{R} \$ 38,3$ bilhões em 2012. O crescimento médio real do PIB dos três segmentos, no período de 2007 a 2012 foi acima do crescimento médio do país e diferente da indústria de transformação como um todo, que registrou queda no mesmo período (MEYGE, 2013).

Com números expressivos e alta concorrência, a cadeia têxtil e de confecção busca de modo constante reduzir os custos de produção para gerar melhores margens comerciais. Dentro do setor de confecção, o processo produtivo de produtos do vestuário é composto por diferentes etapas que possuem impactos distintos no custo de produção. Uma das fases do processo produtivo que tem grande influência no valor da peça final é a etapa de encaixe de moldes no tecido para posterior corte.

A etapa de encaixe consiste em inserir os moldes que possuem, em sua maioria, formato irregular dentro de um retângulo, o tecido. $O$ encaixe é feito considerando-se uma camada de tecido, porém na etapa de corte os moldes são cortados sobre o enfesto, onde diversas camadas de tecido são colocadas umas sobre as outras.

Os problemas de encaixe e corte têm como objetivo maximizar ou minimizar uma determinada função objetivo, por este motivo são classificados como problemas de otimização. Como a quantidade de peças é finita, o problema é definido como otimização combinatória. O problema de encaixe bidimensional de formas irregulares é geometricamente complexo e, portanto, difícil de implementar e requer considerável esforço computacional. Os problemas reais, muitas vezes, precisam lidar com muitas peças e com um pequeno tempo computacional para gerar leiautes de encaixe.

O processo de encaixe é uma das etapas mais difíceis de ser realizada, tanto manualmente quanto computacionalmente, já que a dificuldade para arranjar as peças aumenta exponencialmente com o incremento da quantidade de moldes. O processo de encaixe se torna especialmente difícil se o tecido tem figuras complexas, xadrezes ou listras, que devem ter continuidade após a etapa de costura da roupa. Uma peça do vestuário confeccionada em tecido listrado, por exemplo, cria a necessidade de diversas etapas exclusivas para o seu processo produtivo: o setor de desenvolvimento precisa especificar o local 
e a continuidade dos padrões; o setor de modelagem desenvolve os moldes da peça com a indicação dos locais de coincidência dos padrões nos moldes; na etapa de encaixe executa-se a disposição dos moldes sobre o tecido, considerando os locais de coincidência; e, na etapa de costura, as partes de tecido cortadas precisam ser unidas com precisão.

Dentre todas essas etapas, o encaixe de moldes em tecidos listrados é um problema prático de difícil solução, conhecido por apresentar baixa eficiência de encaixe, porém de grande importância para a competitividade da indústria de confecção e também com repercussão e aplicação científica. Dessa forma, este artigo apresenta o estado da arte dos problemas bidimensionais de encaixe de formas irregulares, aborda os requisitos necessários para o encaixe de moldes em tecidos listrados e propõe um algoritmo para o problema baseado na representação gráfica dos moldes e do tecido.

\section{FUNDAMETAĈ̣AO TEÒRICA \\ Estado da arte dos problemas bidimensionais de corte e encaixe de formas irregulares}

Nos últimos anos, o volume de publicações que abordam os problemas de encaixe bidimensionais de formas irregulares aumentou significativamente, assim como a qualidade das técnicas empregadas. Desse modo, não é possível fornecer uma completa e exaustiva revisão bibliográfica sobre o assunto nesta seção. Dowsland e Dowsland (1995), Nielsen e Odgaard (2003) e Bennell e Oliveira (2008) apresentam pesquisas com revisão bibliográficas aprofundadas sobre o tema.

Bennell e Oliveira (2008) também publicaram um tutorial sobre as possibilidades de abordagem geométrica para os problemas de encaixe e corte. Os autores evidenciam que a quantidade de publicações não é condizente com a importância do problema para as indústrias. Eles acreditam que uma explicação para isso seja a dificuldade e o tempo necessário para desenvolver uma ferramenta geométrica que lide de modo eficiente com o problema.

Entre os trabalhos mais recentes, destacam-se os algoritmos GLSHA ${ }^{13}$ e SAHA ${ }^{14}$, propostos por Gomes e Oliveira (2006); 2DNest, apresentado em Egeblad, Nielsen e Odgaard (2007); two-stage packing, publicado em Wong et al. (2009); polígono no-fit com linha e arco, apresentado por Burke et al. (2010); ELS, proposto por Leung, Lin e Zhang (2012); algoritmo híbrido utilizando o

13 Simulated annealing hybrid algorithm

14 Greedy local search hybrid algorithm 
Cuckoo search, publicado em Elkeran (2013); algoritmo para encaixe em tecidos com figuras complexas, apresentado por Ko e Kim (2013); e algoritmos para encaixe em matérias-primas com defeitos, denominados de $\mathrm{SNH} 1, \mathrm{SNH} 2, \mathrm{SNH} 3$ e Heurística Lagrangean, publicado em Baldacci et al. (2014).

Para todos os métodos propostos pelas pesquisas citadas, é possível dividir as técnicas em grupos, de acordo com determinados critérios. Há publicações em que as peças, que precisam ser encaixadas na matéria-prima, são consideradas uma de cada vez, e colocadas diretamente sobre o material, de acordo com uma política de colocação. Isso é repetido muitas vezes para diferentes ordenamentos de peças e, ao final, a melhor solução é escolhida. Porém, em outras pesquisas, ao invés de construir encaixes pela colocação de peças, seguindo diferentes ordenamentos e aplicando diferentes critérios de colocação, gera-se uma solução inicial e, em uma segunda fase, iterativamente, tenta-se melhorar o encaixe através de modificações no próprio leiaute.

Outro critério de categorização das pesquisas apresentadas é a abordagem geométrica para resolução do problema, que se concentram em poligonal, predominantemente pelo método do polígono no-fit ${ }^{15}$, ou pela técnica raster ${ }^{16}$. Cada uma apresenta benefícios e desvantagens.

Dentre todos os trabalhos citados, os únicos que fazem referência a tecidos com listras são as pesquisas de Ko e Kim (2013) e Nielsen e Odgaard (2003). Ko e Kim (2013) desenvolveram uma técnica de encaixe para o vestuário confeccionado em tecidos com figuras complexas. Porém, a técnica abordada pelos autores privilegia o processamento da imagem para detectar a repetição do módulo ${ }^{17}$ dos tecidos e não o método de encaixe. Através da técnica desenvolvida é possível ajustar as imagens na roupa interativamente e obter a continuidade dos padrões de repetição nas diferentes partes que compõem a roupa. No final do processo, os moldes da roupa podem ser arranjados sobre o tecido, de modo que a continuidade das figuras seja preservada, enquanto o software busca a minimização da perda de tecido. Ko e Kim (2013) ressaltam que o objetivo principal da pesquisa não é gerar um ótimo encaixe e, por esse motivo, um método simples de encaixe foi empregado.

15 O polígono no-fit de duas peças, por exemplo, $A$ e $B$, é definido como o polígono $\left(\mathrm{NFP}_{A B}\right)$ resultante de uma operação de deslizamento entre as peças $A$ e $B$. A peça $A$ tem uma posição fixa e a peça $B$ é o polígono que move em torno do perímetro da peça $A$ para executar a etapa de deslizamento. $O \mathrm{NFP}_{\mathrm{AB}}$ cria um novo polígono em que as peças A e B sempre se tocam, mas nunca se sobrepõem (BENNELL; OLIVEIRA, 2008).

16 Métodos raster são abordagens que dividem as formas geométricas em uma grade representadas por uma matriz e, assim, reduzem a informação geométrica para a codificação de dados (BENNELL; OLIVEIRA, 2008).

17 O módulo é a unidade da padronagem, ou seja, a menor área que inclui todas as listras que compõem o desenho. Após a repetição do módulo, que pode ter diferentes posições, é gerado o padrão (RÜTHSCHILLING, 2008). 
No trabalho apresentado por Nielsen e Odgaard (2003) há uma seção denominada de restrições diversas. Entre essas restrições, os autores definem a correspondência entre moldes como um problema da indústria do vestuário, em que dois moldes ou mais precisam sempre ser movidos na mesma distância horizontal ou vertical. Para resolver o problema, os autores definem conjuntos de moldes. Dessa forma, é possível resolver alguns problemas, porém sem definições de especificidades.

\section{Desenvolvimento de roupas com listras}

Para poder desenvolver um algoritmo que lide com o encaixe de moldes em tecidos listrados, é preciso primeiramente entender as restrições do problema. Nessa seção, abordam-se alguns exemplos de roupas confeccionadas em tecidos listrados. São apresentados o módulo, a padronagem da listra e a indicação dos pontos de coincidência após a etapa de costura.

Uma das peças do vestuário em que a utilização de listras é frequente é a camisa masculina. A camisa masculina, confeccionada em tecido listrado com módulo pequeno, precisa ter pontos de coincidência no transpasse da frente, nos punhos, nas mangas e nas carcelas. Caso o modelo tenha bolso, também é necessário que as listras do bolso encontrem com as da frente da camisa. A Figura 1 apresenta um exemplo de camisa masculina fabricada em tecido listrado. O ponto de coincidência do transpasse está destacado através de um círculo vermelho e os círculos em amarelo indicam a coincidência da padronagem nos punhos. No caso dos punhos e do transpasse não é necessário que o molde fique em um local específico da listra, mas que o local indicado seja o mesmo para todos os moldes do punho, assim como para todos os moldes da parte da frente.

Figura 01 - Camisa Ermenegildo Zegna

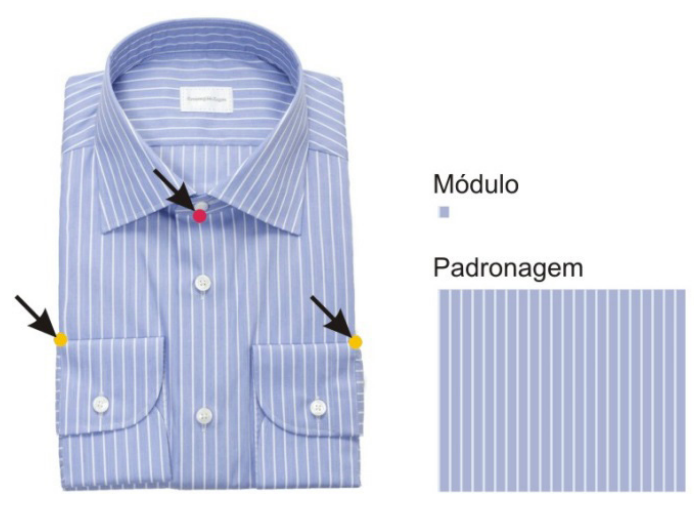

Fonte: Adaptado de Zegna (2014). 
A Figura 2 apresenta outro exemplo de camisa com o módulo maior de listra, em que fica evidente a necessidade dos pontos de coincidência. Neste exemplo, o tamanho do molde do punho é menor do que o módulo das listras. Assim, o mais importante é que os moldes do punho sejam colocados no mesmo local da listra. Os pontos de coincidência para as mangas da camisa, destacados pelos círculos pretos na Figura 2, também são fundamentais. Para camisas confeccionadas com módulo de listras em que a posição do módulo altera a estética da camisa, o molde das costas também deve ter um ponto de coincidência central. Para que as mangas fiquem com o mesmo padrão de listra, os moldes devem ter o mesmo ponto de coincidência e serem encaixados da seguinte forma: o molde da manga direita sem rotação e o molde da manga esquerda com rotação de $180^{\circ}$ ou o contrário. É possível observar na Figura 2 que houve uma preocupação com a localização dos moldes da manga no módulo da listra, porém nenhum molde rotacionou $180^{\circ}$.

Figura 02 - Camisa Polo Ralph Lauren

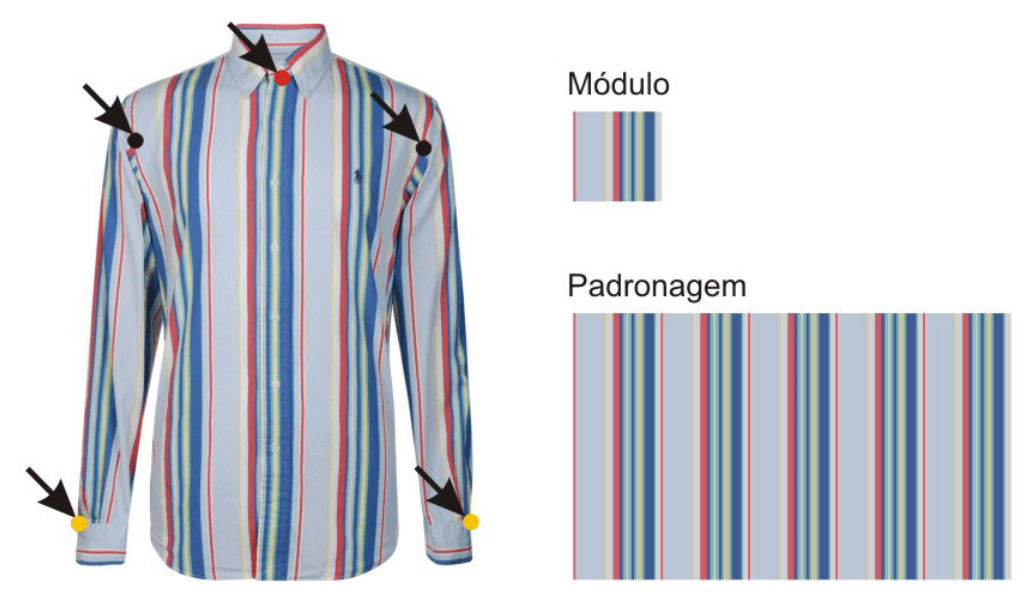

Fonte: Adaptado de Lauren (2014).

Outra peça do vestuário em que é comum a utilização de listras são os suéteres. A Figura 3 apresenta um exemplo de suéter feminino confeccionado em malha retilínea e com padronagem listrada. Nessas peças, o ponto de coincidência das listras é na parte inferior da cava, tanto para os moldes da frente e costas como para os moldes da manga. Todos esses moldes devem ficar com a mesma altura no módulo durante a etapa de encaixe. É possível observar que o módulo de repetição é maior do que os moldes que compõem o suéter. 
Figura 03 - Suéter Vince

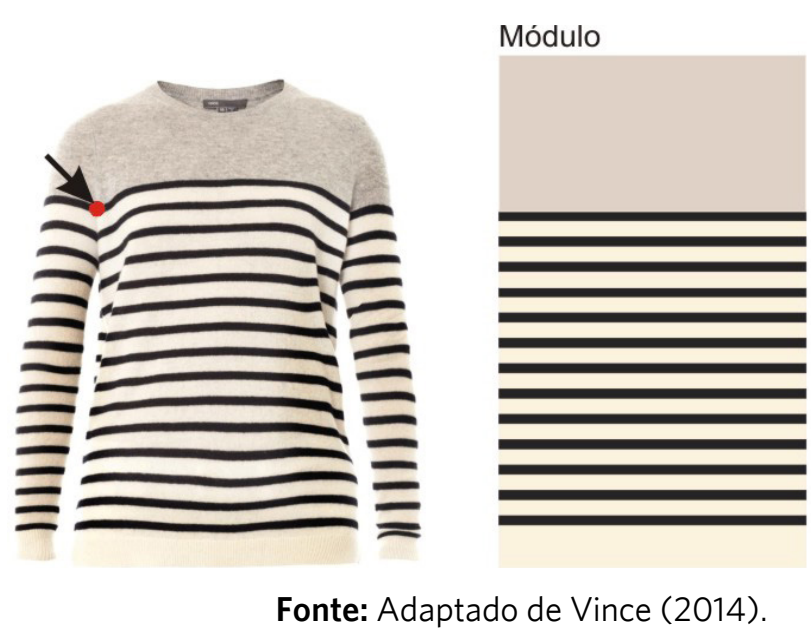

\section{Abordagem proposta para o encaixe em tecidos lisos e listrados}

Nesta seção é apresentada a representação gráfica das formas e software de encaixe para tecido liso (seção 4.1) e algoritmo de encaixe para tecido listrado (seção 4.2).

\section{Representação gráfica das formas e software de encaixe para tecido liso}

Após a definição dos pontos de coincidência e das restrições em relação às possibilidades de posicionamento e rotação dos moldes, é preciso definir como todas essas informações são representadas graficamente para a resolução do problema de modo automatizado. Para os dois tipos de formas geométricas envolvidos no problema, o tecido e os moldes, a representação gráfica é feita através do método raster.

Para representar uma forma através do método raster são necessários alguns passos sistemáticos. Primeiro, a forma é contornada por um retângulo envolvente. Depois, o espaço é dividido em grids. Os grids possuem a mesma dimensão, independente do tamanho do molde, a diferença será a quantidade de grids para representar cada molde. Em Alves e Aymone (2013) é apresentado como esse processo é feito computacionalmente.

O objetivo da divisão das formas em grids é a possibilidade de inserção de conteúdos nesses grids para a transmissão de informações. No presente trabalho utilizam-se conteúdos numéricos e cores. Os números são empregados para a identificação da posição de um determinado grid no molde ou no tecido. 
São utilizados os números 0,1 e 3 . O número 0 identifica um grid vazio; o número 1 , o contorno de um molde; e o número 3 , o interior de um molde. A representação do raster dos moldes (fig. 04) é feita de modo semelhante ao proposto por Segenreich e Braga (1986 apud BENNELL; OLIVEIRA, 2008).

Figura 04 - Representação gráfica do molde de um modelo de biquíni através do método raster

\begin{tabular}{|l|llllllllllllllllllllllll|}
\hline 1 & 1 & 1 & 1 & 1 & 1 & 1 & 1 & 1 & 1 & 1 & 1 & 1 & 1 & 1 & 1 & 1 & 1 & 1 & 1 & 1 & 1 & 1 \\
0 & 1 & 3 & 3 & 3 & 3 & 3 & 3 & 3 & 3 & 3 & 3 & 3 & 3 & 1 & 1 & 1 & 1 & 1 & 1 & 0 & 0 & 0 \\
0 & 0 & 1 & 3 & 3 & 3 & 3 & 3 & 3 & 3 & 1 & 1 & 1 & 1 & 0 & 0 & 0 & 0 & 0 & 0 & 0 & 0 & 0 \\
0 & 0 & 1 & 3 & 3 & 3 & 3 & 3 & 1 & 1 & 0 & 0 & 0 & 0 & 0 & 0 & 0 & 0 & 0 & 0 & 0 & 0 & 0 \\
0 & 0 & 1 & 1 & 3 & 3 & 1 & 1 & 0 & 0 & 0 & 0 & 0 & 0 & 0 & 0 & 0 & 0 & 0 & 0 & 0 & 0 & 0 \\
0 & 0 & 0 & 1 & 1 & 1 & 0 & 0 & 0 & 0 & 0 & 0 & 0 & 0 & 0 & 0 & 0 & 0 & 0 & 0 & 0 & 0 & 0 \\
0 & 0 & 0 & 0 & 1 & 0 & 0 & 0 & 0 & 0 & 0 & 0 & 0 & 0 & 0 & 0 & 0 & 0 & 0 & 0 & 0 & 0 & 0 \\
\hline
\end{tabular}

Fonte: Elaborado pelos Autores

O tecido, no início do encaixe, sempre está totalmente vazio. Dessa forma, todos os grids do tecido contém o número 0. A Figura 5 apresenta a representação gráfica de uma parte do tecido antes do início do encaixe.

Figura 05 - Representação gráfica de um tecido liso

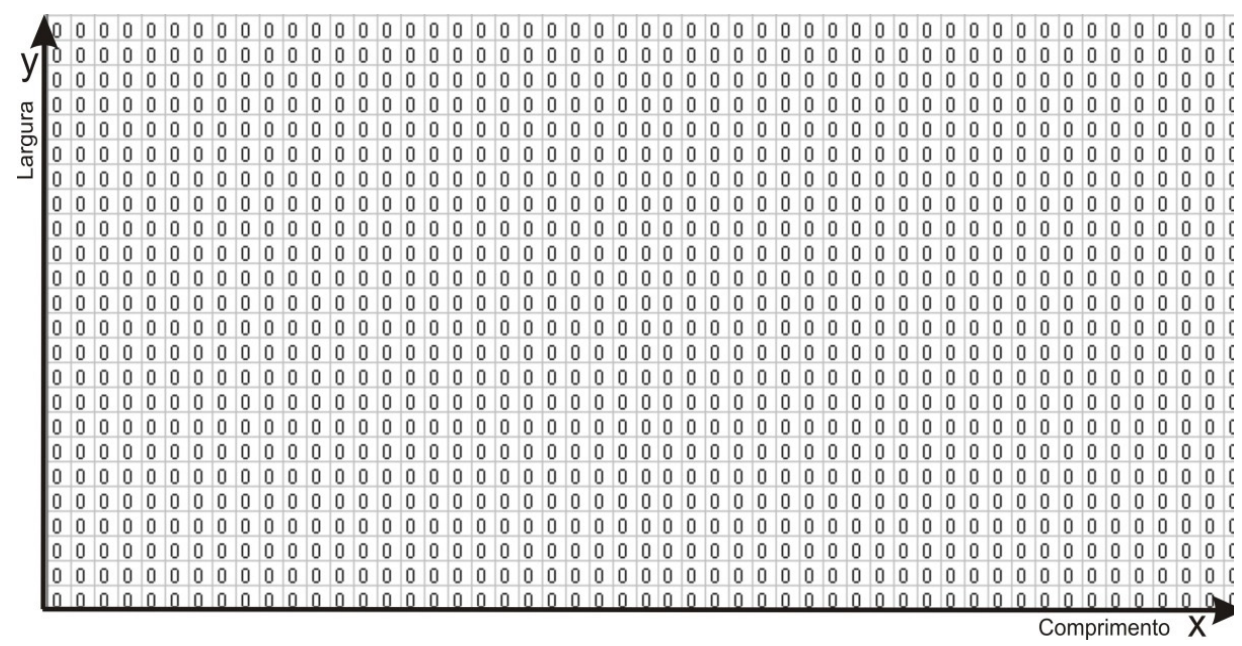

Fonte: Elaborado pelos Autores

A cada etapa, e conforme os moldes são encaixados no tecido, os números contidos nos moldes passam para o tecido. Os conteúdos numéricos auxiliam o processo de encaixe através da detecção de moldes sobrepostos. Para saber se dois moldes se sobrepõem, os conteúdos numéricos dos grids dos dois moldes são somados. Se o resultado da soma for 2, dois contornos de moldes se encostam. Caso o resultado seja 4 , o contorno de um molde está sobre a parte interna de outro molde. Se o resultado da soma for 6 , o interior dos dois moldes estão se sobrepondo. 
A utilização do método raster na representação gráfica dos moldes e do tecido possui diversas vantagens. É possível representar qualquer forma geométrica, seja ela com concavidades ou buracos. Uma região com defeito no tecido pode ser facilmente identificada através da inserção do número 3 nos grids. É possível calcular a área de cada molde e o percentual de eficiência do encaixe, através da identificação e relação entre os grids ocupados e a área total. É possível inserir conteúdos em cada grid dos moldes e do tecido que representam informações sobre uma determinada posição.

Para o encaixe de moldes em tecidos lisos foi desenvolvido, durante o mestrado em Design (ALVES, 2010), o software Riscare. O software está registrado no Instituto Nacional de Propriedade Industrial (INPI) do Brasil com o número 12048-2. A Figura 6 mostra a interface do software Riscare com o encaixe de duas camisas masculinas. O problema apresentado obteve uma eficiência de $83,90 \%$. Os moldes da Figura 6 foram publicados pela primeira vez em Wong et al. (2009).

Figura 06 - Encaixe de duas camisas masculinas no software Riscare

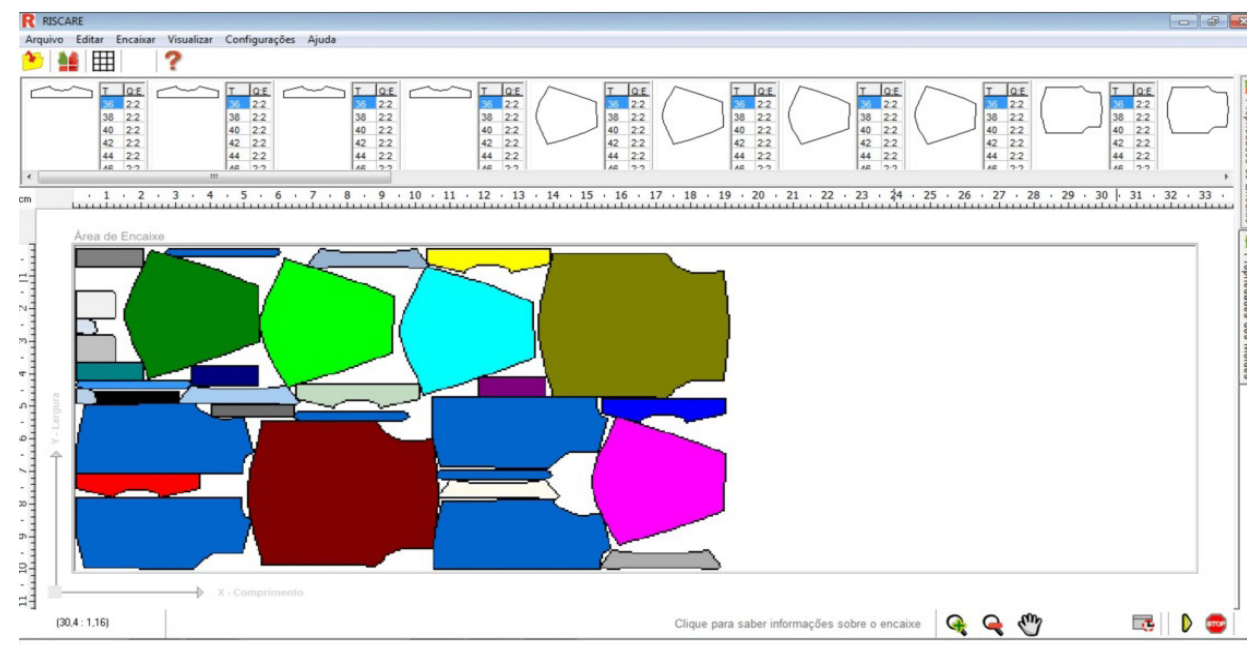

Fonte: Elaborado pelos Autores

\section{A representação gráfica das formas e algoritmo de encaixe para tecidos listrados}

Para tecidos listrados, além do conteúdo numérico, os grids também contêm cores. As cores são empregadas especificamente para auxiliar o encaixe de moldes em tecidos listrados. Como mostrado na seção 3, alguns moldes de peças do vestuário, confeccionadas em tecidos listrados, precisam ter pontos de coincidência. Esses pontos indicam as posições específicas que um determinado molde deve ficar em relação ao módulo da listra. Essas posições podem ser as mesmas para mais de um molde, como no caso do transpasse 
da frente da camisa social masculina. Assim, para cada posição específica de um molde ou de um conjunto de moldes, utiliza-se a mesma cor. Para posições diferentes no módulo, usam-se cores diferentes. A Figura 7 apresenta um exemplo da utilização de cores e de conteúdos numéricos nos grids para a representação gráfica de um molde.

Figura 07 - Representação gráfica do molde da frente de uma camisa masculina através do método raster

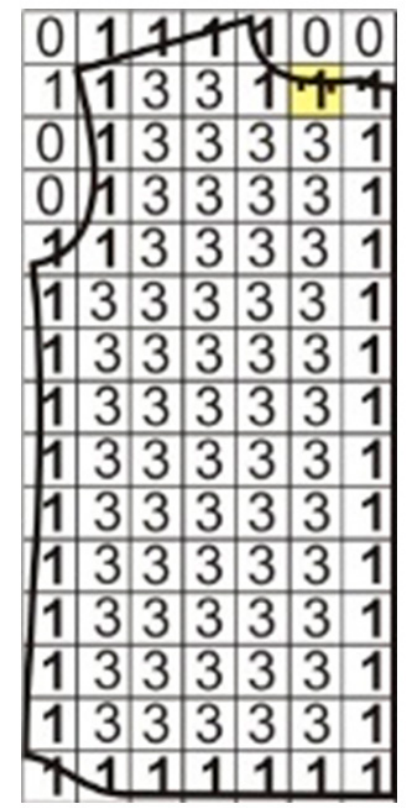

Fonte: Elaborado pelos Autores

Na Figura 7 o molde apresentado está com grids de dimensões muito superiores ao utilizado no sistema computacional e do apresentado na Figura 4, quando comparados aos tamanhos reais dos dois moldes. Isso se deve ao fato de que a Figura 7 foi construída para uma simulação. Os grids preenchidos por cores e o algoritmo proposto para o encaixe de moldes em tecidos listrados é uma nova proposta e está em fase de implementação no software Riscare. Assim, os moldes são representados inicialmente com um número reduzido de grids para facilitar a simulação do processo e verificação de erros.

No presente trabalho considera-se que o tecido pode ter listras verticais, paralelas ao comprimento do tecido, e horizontais, paralelas à largura do tecido. A representação do início do módulo também é feita através do emprego de cor nos grids. A Figura 8 mostra a representação gráfica de uma parte do tecido com listras paralelas ao comprimento, os grids que estão no início do módulo de repetição possuem a cor azul. 
Figura 08 - Tecido com listras paralelas ao comprimento representado pelo método raster

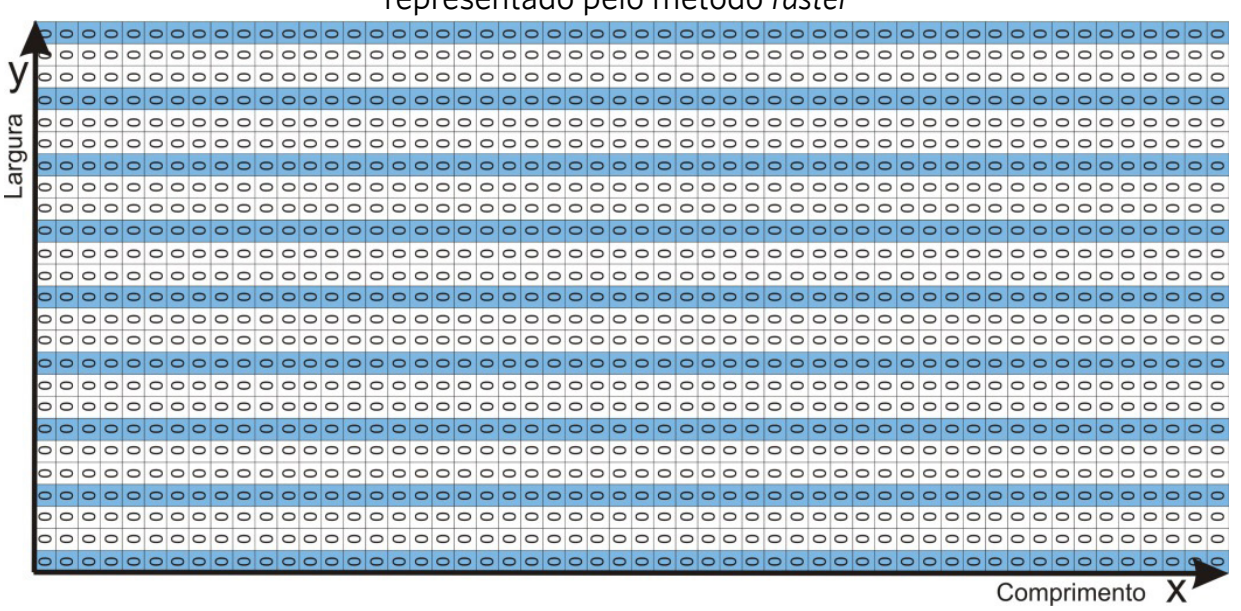

Fonte: Elaborado pelos Autores

Para implementar no software Riscare o encaixe em tecidos listrados, será utilizada a representação gráfica para os moldes e o tecido descrita na seção 4.1. A identificação dos pontos de coincidência dos moldes através de grids coloridos é inédita na literatura e fundamental para o algoritmo proposto e para a etapa inicial de pré-processamento.

Inicialmente é necessário que o usuário forneça as seguintes informações: moldesqueserãoencaixados, indicaçãodosmoldesquepossuemrelacionamento e pontos de coincidência, a localização dos pontos de coincidência em relação ao módulo de repetição da listra, as possibilidades de rotação dos moldes e a distância de repetição do módulo no tecido.

Após isso, tem-se a etapa de pré-processamento, onde os moldes são divididos em grandes, médios e pequenos. Os moldes grandes e médios compõem um grupo e os moldes pequenos um segundo grupo. Em seguida, fazse uma combinação por grupo com repetição dos seus moldes. Por exemplo, se a peça é composta por três moldes (frente, costas e manga ${ }^{18}$ ), o molde da frente combina com o molde das costas, da manga e outro da frente. O molde das costas, que já combinou com o molde da frente, também combina com outro molde das costas e o molde da manga. A manga, que já combinou com os outros moldes, também combina com outro molde de manga. Os moldes são combinados entre eles porque normalmente o encaixe é feito com mais de uma peça do mesmo modelo.

Para cada uma dessas combinações de dois moldes, na etapa de préprocessamento, os moldes são rotacionados nas orientações admissíveis e deslocados em todas as direções possíveis. Ao final dessa etapa, obtém-se um 18 Considera-se, para o exemplo, um molde de manga verticalmente simétrico. 
conjunto com todas as posições existentes entre dois moldes. Para cada uma dessas posições, é calculada a eficiência de encaixe. Todo esse conjunto de informações é utilizado para o encaixe dos moldes dentro do tecido.

O encaixe inicia com ordenamento das eficiências obtidas na etapa de pré-processamento. Após essa etapa, é inserido um molde no canto inferior esquerdo do tecido. O segundo molde inserido no encaixe é aquele que obteve melhor eficiência com o primeiro molde na etapa de pré-processamento. As próximas peças colocadas no tecido seguem o mesmo critério da anterior, eficiência entre dois moldes. Assim, a prioridade é o preenchimento da largura do tecido. Quando não é possível inserir mais nenhum molde na largura do tecido, ou seja, nas partes inferiores ou superiores da largura, um molde é colocado utilizando o comprimento do tecido. A inserção desse molde é feita na região que apresenta maior espaço disponível no comprimento do tecido. O processo é iterativo até que todas as peças sejam inseridas no tecido. Esse processo é realizado para todo o grupo de moldes médios e grandes. Assim, depois que todos os moldes médios e grandes já foram inseridos no tecido, os moldes pequenos, são colocados nos espaços vazios do encaixe.

A Figura 9 apresenta de modo esquemático as principais etapas percorridas pelo algoritmo proposto.

Para verificar a potencialidade do algoritmo proposto para o encaixe em tecidos listrados, antes da implementação completa no software Riscare, fez-se uma simulação manual. Imprimiu-se em papel a representação gráfica de um tecido listrado e dos moldes de três camisas masculinas e construiuse o encaixe seguindo as etapas descritas no algoritmo da Figura 9. Antes de construir o encaixe, também foi feita a etapa de pré-processamento no software CorelDRAW. 
Figura 09 - Algoritmo proposto para o encaixe de moldes em tecidos listrados

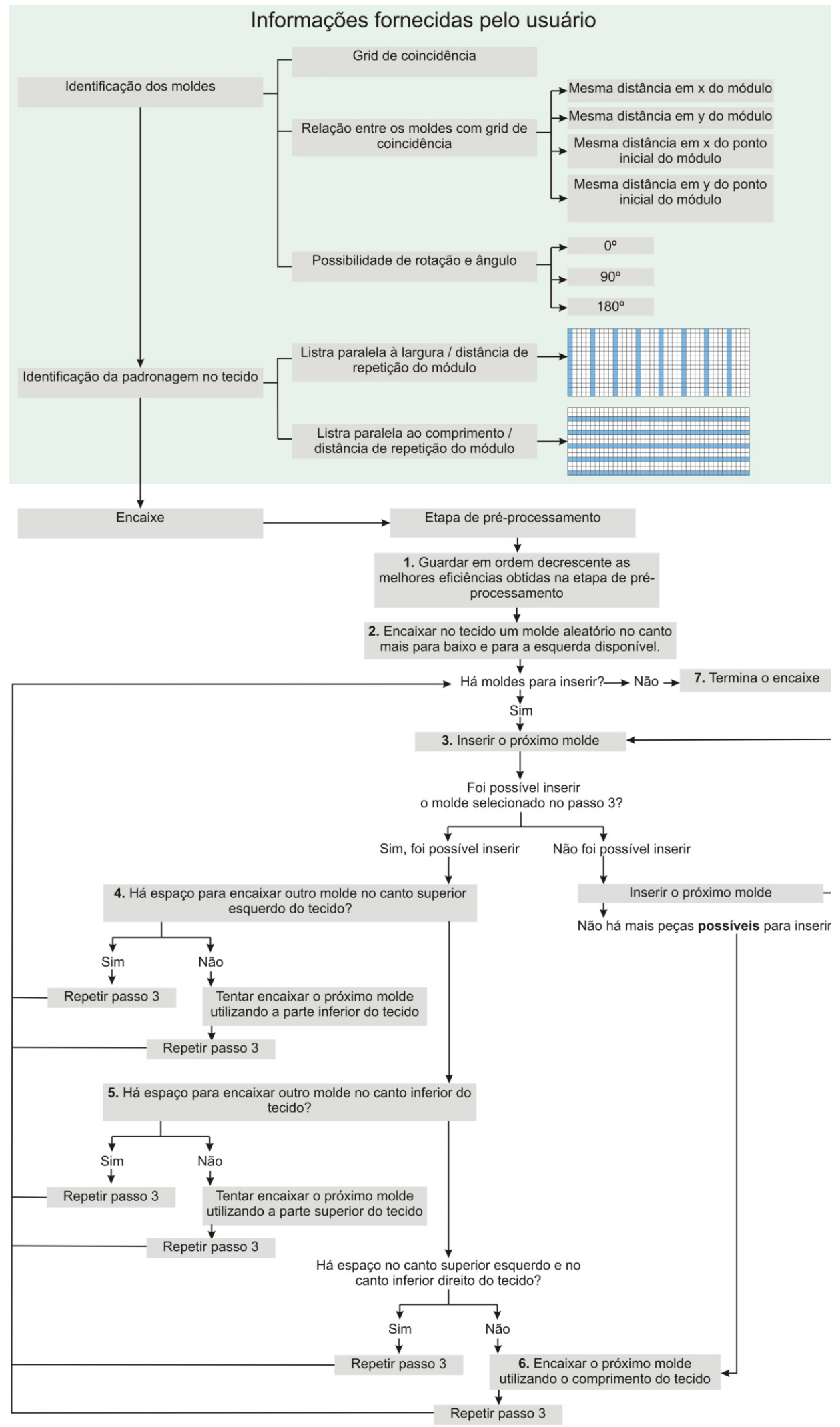

Fonte: Elaborado pelos Autores 
Após a simulação, percebeu-se a necessidade de ajuste de algumas etapas no algoritmo. Essas etapas foram modificadas, e repetiu-se todo o processo de encaixe.

A Figura 10 apresenta o resultado da simulação manual, feita no software CoreIDRAW, com os moldes de uma camisa masculina ${ }^{19}$ empregando-se 0 método raster e grids com informações.

Figura 10 - Encaixe de dois moldes de camisa masculina através do método raster e do algoritmo proposto

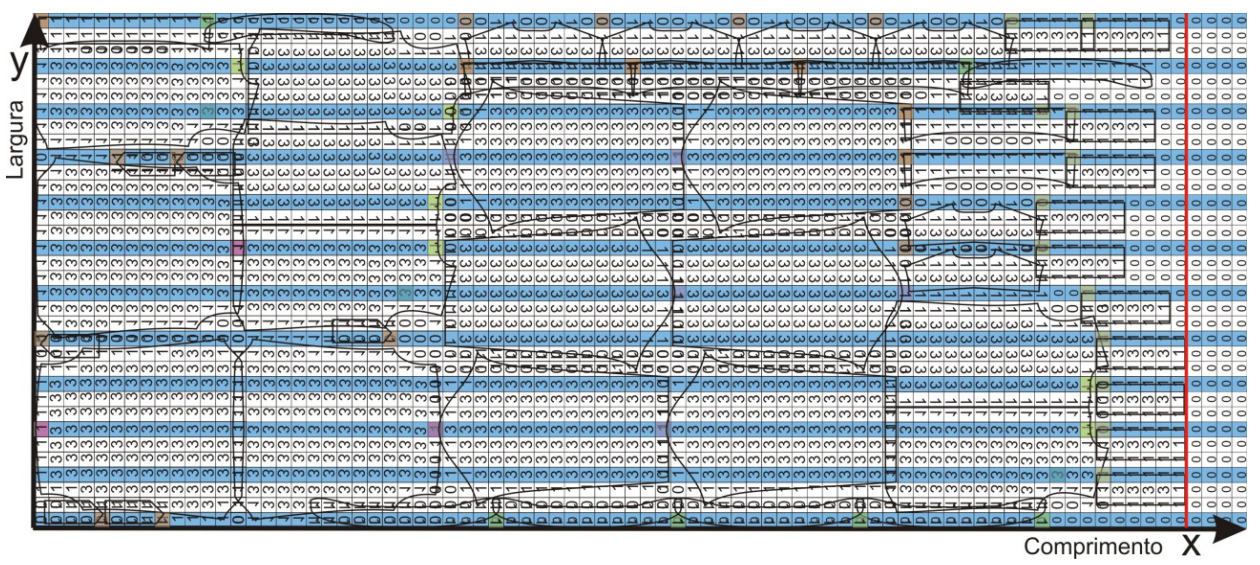

Fonte: Elaborado pelos Autores

No encaixe apresentado da Figura 10 é possível observar que todos os moldes possuem pontos de coincidência: frente, costas, manga, punho, pala, carcela, colarinho e o pé de colarinho. Optou-se por essa configuração porque a dimensão do módulo da listra era grande. Esse tipo de restrição, de um modo geral, diminui a eficiência do encaixe. Porém, como se pode perceber pela Figura 10, o algoritmo proposto obteve um encaixe com ótima utilização do tecido e eficiência de $94,69 \%$.

É importante destacar que a tomada de algumas decisões no algoritmo são aleatórias, como a inserção da primeira peça. Se outro molde for inserido primeiro, no canto inferior esquerdo, toda a organização dos moldes será modificada. Assim, o algoritmo executa o encaixe algumas vezes, iniciando em cada uma delas com diferentes moldes. Ao final, o encaixe que obteve maior eficiência é mostrado para o usuário.

Como citado anteriormente, o tamanho dos grids na Figura 10 estão muito maiores do que quando executado no software Riscare. Essa configuração foi proposital para facilitar a simulação e a verificação da eficiência do algoritmo

19 Os moldes apresentados aqui foram desenvolvidos com o objetivo de fazer uma simulação de encaixe, assim não houve preocupação com a exatidão das medidas. 
proposto. A resolução dos grids interfere mais no tempo de processamento computacional e na visualização dos moldes pelo usuário do que na eficiência do encaixe. Porém, é provável que a eficiência diminua um pouco com o aumento da resolução. A visualização de moldes com pequenas sobreposições na Figura 10 também é decorrência da resolução dos grids.

É importante destacar os diversos aspectos positivos e benefícios da abordagem proposta. Todos os moldes possuem as mesmas posições das listras em todos os lugares. Após a etapa de corte, não é preciso separar os moldes em grupos para a etapa de costura, já que todas as partes possuem as listras no mesmo local. Outro ponto positivo é que todas as peças confeccionadas apresentam o mesmo aspecto. Para que isso seja possível, não houve considerável perda de matéria-prima, uma vez que a eficiência de utilização do tecido foi alta. Além disso, o usuário pode identificar a localização específica do módulo da listra para cada molde. O processo é $100 \%$ automatizado, assim não é preciso que o usuário encaixe manualmente nenhum dos moldes. Para o exemplo apresentado, foi escolhido um dos casos mais difíceis de obter uma boa eficiência, um módulo de listra grande. Desse modo, acredita-se que para módulos de tamanhos menores possa se obter eficiências ainda melhores.

\section{CONSIDERAC̣̃̃ES FINAIS}

Neste trabalho foi apresentado um algoritmo que atende as restrições necessárias para o encaixe de moldes em tecidos listrados. O algoritmo proposto obteve elevada eficiência na disposição dos moldes sobre o tecido listrado e pode ser utilizado para diferentes peças do vestuário com distintas restrições. Ele está em fase de implementação no software Riscare e faz parte da Tese de Doutorado em andamento da autora.

Listra, enquanto padrão de tecidos, é a estampa mais utilizada no mundo (CHATAIGNIER, 2006). Une-se a esse fato o grande volume de produção e consumo de produtos do vestuário e a falta de publicações científicas sobre o problema de produção desse tipo de vestuário. Softwares comerciais que lidam com o problema de encaixe em tecidos listrados apresentam limitações ou possuem alto valor de aquisição. A partir desses dados, conclui-se empiricamente que uma grande quantidade de peças do vestuário confeccionadas em tecidos listrados é produzida sem a preocupação de coincidência das listras após a etapa de costura. Tal fato pode ser visto com frequência em peças de roupas comercializadas.

$\mathrm{Na}$ indústria do vestuário, o custo da matéria-prima representa um percentual elevado do custo do produto final. Assim, a redução do desperdício 
de matéria-prima influencia no custo do produto acabado. Dessa forma, um software que execute o encaixe de moldes em tecidos listrados e que respeita as restrições do processo produtivo é fundamental na diminuição do desperdício de matéria-prima, na obtenção de lucro para a empresa, na produção de um produto de melhor qualidade para o consumidor e na diminuição do impacto ambiental e na melhoria da eficiência do processo produtivo.

\section{REFERÊNCIAS}

ALVES, A. S. Design do vestuário: técnica e software de encaixe de moldes no tecido. 2010. Dissertação (Mestrado) - Universidade Federal do Rio Grande do Sul, Porto Alegre, 2010.

ALVES, A. S.; AYMONE, J. L. F. Representação gráfica de moldes em um software para o design do vestuário. In: INTERNATIONAL CONFERENCE ON GRAPHICS ENGINEERING FOR ARTS AND DESIGN, 10., 2013, Florianópolis. Anais ..., Florianópolis, 2013.

BALDACCI, R.; BOSCHETTI, M. A.; GANOVELLI, M.; MANIEZZO, V. Algorithms for nesting with defects. Discrete Applied Mathematics, Amsterdam, v. 163, p. 17-33, 2014.

BENNELL, J. A.; OLIVEIRA, J. F. The geometry of nesting problems: a tutorial. European Journal of Operational Research, Amsterdam, v. 184, p. 397-415, 2008.

BURKE, E. K.; HELLIER, R. S. R.; KENDALL, G.; WHITWELL, G. Irregular Packing Using the Line and Arc No-Fit Polygon. Operations Research, Baltimore, v. 58, p. 948-970, 2010.

CHATAIGNIER, G. Fio a fio: tecidos, moda e linguagem. São Paulo: Estação das Letras Editora, 2006.

DOWSLAND, K. A.; DOWSLAND, W. B. Solution approaches to irregular nesting problems. European Journal of Operational Research, Amsterdam, v. 84, p. 506-521, 1995.

EGEBLAD, J.; NIELSEN, B. K.; ODGAARD, A. Fast Neighborhood search for two- and three-dimensional nesting problems. European Journal of Operational Research, Amsterdam, v. 183, p. 1249-1266, 2007.

ELKERAN, A. A new approach for sheet nesting problem using guided cuckoo search and pairwise clustering. European Journal of Operational 
Research, Amsterdam, v. 231, p. 757-769, 2013.

GOMES, A. M.; OLIVEIRA, J. F. Solving Irregular Strip Packing problems by hybridising simulated annealing and linear programming. European Journal of Operational Research, Amsterdam, v.171, p. 811-829, 2006.

KO, E.; KIM, S. Garment Pattern Nesting Using Image Analysis and Three-Dimensional Simulation. Fibers and Polymers, v. 14, p. 860-865, 2013.

LAUREN, P. R. Varied Stripe Logo Shirt in Blue Mid. Disponível em: <http://www.ebay.co.uk/itm/POLO-RALPH-LAUREN-Varied-StripeLogo-Shirt-in-BLUE-MID-/261138133459>. Acesso em: 19 fev. 2014.

LEUNG, S. C. H.; LIN, Y.; ZHANG, D. Extended local search algorithm based on nonlinear programming for two-dimensional irregular strip packing problem. Computers \& Operations Research, New York, v. 39, p. 678-686, 2012.

MEYGE, A. Varejo e confecção crescem, mas têxtil recua. Valor Econômico, São Paulo, jul. 2013. Disponível em:< http://www.valor. com.br/empresas/3203308/varejo-e-confeccao-crescem-masindustria-textil-recua\#>. Acesso em: 17 fev. 2014.

NIELSEN, B. K.; ODGAARD, A. Fast Neighborhood Search for the Nesting Problem. Copenhagen: Technical Report. University of Copenhagen, 2003.

RÜTHSCHILLING, E. A. Design de Superfície. Porto Alegre: Editora da UFRGS, 2008.

STECANELLA, V. Setor têxtil deve faturar menos em 2012 do que em 2011. Istoé Dinheiro, São Paulo, jan. 2013. Disponível em: <http://www.istoedinheiro.com.br/noticias/109931_ SETOR+TEXTIL+DEVE+FATURA+MENOS+EM+2012+DO+2011.

Acesso em: 14 fev. 2014.

VINCE. Breton stripe cashmere sweater. Disponível em:<http://www. matchesfashion. com/product/176604>. Acesso em: 19 fev. 2014.

WONG ET AL. (2009). citado e nao consta referencia 
ZEGNA, E. Sky blue striped dress shirt. Disponível em:<http://www. robertold.co.uk/ ermenegildo-zegna-shirt-sky-blue-stripe.html>. Acesso em: 19 fev. 2014.

Recebido em:27/05/14

Aprovado em:30/06/14 